Western University

Scholarship@Western

Chemistry Publications

Chemistry Department

$10-6-2010$

Ytterbium triflate catalyzed synthesis of alkoxysubstituted donor-acceptor cyclobutanes and their formal $[4+2]$ cycloaddition with imines: stereoselective synthesis of piperidines.

Mahmoud M Abd Rabo Moustafa

Brian L Pagenkopf

Follow this and additional works at: https://ir.lib.uwo.ca/chempub

Part of the Chemistry Commons

Citation of this paper:

Moustafa, Mahmoud M Abd Rabo and Pagenkopf, Brian L, "Ytterbium triflate catalyzed synthesis of alkoxy-substituted donoracceptor cyclobutanes and their formal [4 + 2] cycloaddition with imines: stereoselective synthesis of piperidines." (2010). Chemistry Publications. 47.

https://ir.lib.uwo.ca/chempub/47 


\section{Ytterbium Triflate Catalyzed Synthesis of Alkoxy-Substituted Donor-Acceptor Cyclobutanes and their Formal [4+2] Cycloaddition with Imines: Stereoselective Synthesis of Piperidines}

\section{Mahmoud M. Abd Rabo Moustafa and Brian L. Pagenkop*}

The University of Western Ontario, Department of Chemistry, London, Ontario, N6A

5B7, Canada

bpagenko@uwo.ca

Received Date (will be automatically inserted after manuscript is accepted)

\section{ABSTRACT}

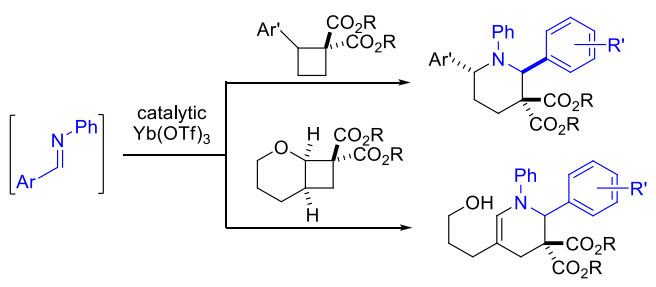

A new synthesis of 2-alkoxy-1,1-cyclobutane diesters and their first use in dipolar cycloadditions is reported. Both the formation of the donor-acceptor cyclobutanes and their subsequent annulation with in situ formed imines are catalyzed by catalytic $\mathrm{Yb}(\mathrm{OTf})_{3}$. Cyclobutanes with carbon donor groups give piperidines with high trans stereoselectivity.

Due to their unique reactivity profiles and inherent strain energy, cyclopropanes and cyclobutanes have emerged as important pharmacophores and versatile building blocks in modern organic synthesis., ${ }^{1,2}$ Lewis acid-catalyzed dipolar cycloadditions involving donoracceptor (DA) cyclopropanes are well documented and have been employed extensively for the preparation of different heterocycles, ${ }^{3}$ including those leading to the

(1) (a) Donaldson, W. A. Tetrahedron 2001, 57, 8589-8627. (b) Rubin, M.; Rubina, M.; Gevorgyan, V. Chem. Rev. 2007, 107, $3117-$ 3179.

(2) (a) Lee-Ruff, E.; Mladenova, G. Chem. Rev. 2003, 103, 14491483. (b) Namyslo, J. C.; Kaufmann, D. E Chem. Rev. 2003, 103, $1485-1537$.

(3) For DA cyclopropane reviews, see: (a) Wenkert, E. Acc. Chem. Res. 1980, 13, 27-31. (b) Reissig, H.-U. Top. Curr. Chem. 1988, 144, 73-135. (c) Reissig, H.-U.; Zimmer, R. Chem. Rev. 2003, 103, 1151- synthesis of natural products. ${ }^{4}$ The ring fission can occur via an $\mathrm{S}_{\mathrm{N}} 2$ type mechanism, by ring opening and subsequent electrophilic trapping, rearrangement, and

1196. (d) Yu, M.; Pagenkopf, B. L. Tetrahedron 2005, 61, 321-347. (e) De Simone, F.; Waser, J. Synthesis 2009, 20, 3353-3374. For selected examples, see: (f) Lautens, M.; Han,W. J. Am. Chem. Soc. 2002, 124, 6312-6316. (g) Young, I. S.; Kerr, M. A. Angew. Chem., Int. Ed. 2003, 42, 3023-3026. (h) Bajtos, B.; Yu, M.; Zhao, H.; Pagenkopf, B. L. J. Am. Chem. Soc. 2007, 129, 9631-9634. (i) Perreault, C.; Goudreau, S. R.; Zimmer, L. E.; Charette, A. B. Org. Lett. 2008, 10, 689-692. (j) Moustafa, M. M. A. R.; Pagenkopf, B. L. Org. Lett. 2010, 12, 3168 3171.

(4) For a review, see: (a) Carson, C. A.; Kerr, M. A. Chem. Soc. Rev. 2009, 38, 3051-3060; For selected examples: (b) Young, I. S.; Kerr, M. A. J. Am. Chem. Soc. 2007, 129, 1465-1469. (c) Bajtos, B.; Pagenkopf, B. L. Eur. J. Org. Chem. 2009, 1072-1077. (d) Jung, M. E.; Chang, J. J. Org. Lett. 2010, 12, 2962-2965. 
ring contraction or expansion. ${ }^{5}$ In contrast, reports that extend similar synthetic transformations to DA cyclobutanes are comparatively rare (Scheme 1). In this regard, aldehydes have been found to undergo [4+2] cycloadditions with DA cyclobutanes, which was first demonstrated by Saigo in $1991 .^{6}$ More recently, Matsuo has extended this work to cyclobutanones, ${ }^{7}$ while Christie and Pritchard, ${ }^{8}$ and Johnson ${ }^{9}$ have demonstrated the effective use of carbon-based activating groups. Although Saigo obtained a mixture of stereoisomers with his amine activated cyclobutanes, subsequent reports have disclosed that ring opening and cycloaddition occurred smoothly to afford tetrahydropyrans in moderate to excellent diastereoselectivity. ${ }^{7,8,9}$

Scheme 1. Cyclopropanes and cyclobutanes as dipolar equivalents

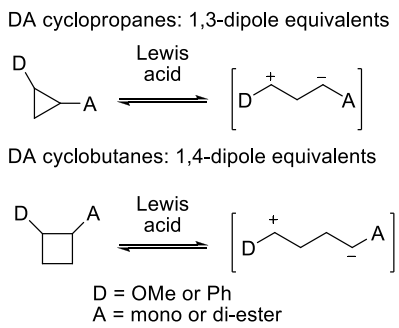

Imines have been utilized by $\mathrm{us}^{3 \mathrm{~d}}$ and others ${ }^{10}$ as dipolarophiles in Lewis acid-catalyzed [3+2] cycloadditions with DA cyclopropanes to furnish pyrrolidine derivatives in a stereoselective manner. At the onset of this project there were no reports that extend this to DA cyclobutanes, ${ }^{11}$ thus we sought to access the piperidine nucleus through a Lewis acid-catalyzed formal [4+2] cycloaddition of appropriately substituted DA cyclobutanes and imines (Scheme 2).Given our ongoing

(5) (a) Karadeolian, A.; Kerr, M. A. J. Org. Chem. 2007, 72, 1025110253. (b) Sapeta, K.; Kerr, M. A. J. Org. Chem. 2007, 72, 8597-8599. (c) Pohlhaus, P. D.; Sanders, S. D.; Parsons, A. T.; Li, W.; Johnson, J. S. J. Am. Chem. Soc. 2008, 130, 8642-8650.

(6) Shimada, S.; Saigo, K.; Nakamura, H.; Hasegawa, M. Chem. Lett. 1991, 20, 1149-1152.

(7) (a) Matsuo, J.-I.; Sasaki, S.; Tanaka, H.; Ishibashi, H. J.; J. Am. Chem. Soc. 2008, 130, 11600-11601. (b) Matsuo, J.-I.; Sasaki, S.; Hoshikawa, T.; Ishibashi, H. Org. Lett. 2009, 11, 3822-3825. (c) Matsuo, J.-I.; Negishi, S.; Ishibashi, H. Tetrahedron Lett. 2009, 50, 5831-5833.

(8) Allart, E. A.; Christie, S. D. R.; Pritchard, G. J.; Elsegood, M. R. Chem. Commun. 2009, 7339-7341.

(9) Parsons, A. T.; Johnson, J. S. J. Am. Chem. Soc. 2009, 131, $14202-14203$

(10) (a) Alper, P. B.; Meyers, C.; Lerchner, A.; Siegel, D. R. Carreira, E. M. Angew. Chem., Int. Ed. 1999, 38, 3186-3189. (b) Lautens, M.; Han,W.; Liu, J. H.-C. J. Am. Chem. Soc. 2003, 125, 40284029. (c) Bertozzi, F.; Gustafsson, M.; Olsson, R. Org. Lett. 2002, 4, 3147-3150. (d) Carson, C. A.; Kerr, M. A. J. Org. Chem. 2005, 70, 8242-8244. (e) Xing, S.; Pan,W.; Liu, C.; Ren, J.; Wang, Z. Angew. Chem. Int. Ed. 2010, 49, 3215-3218.

(11) While this manuscript was in preparation, Matsuo reported a [4+2] cycloaddition between cyclobutanones and imines. See: Matsuo, J.-I.; Okado, R.; Ishibashi, H. Org. Lett. 2010, 12, 3266-3268. interest in alkoxy substituted DA cyclopropanes, ${ }^{3 \mathrm{~h}, 3 \mathrm{j}, 12}$ the analogous cyclobutanes were chosen as substrates for the exploration of this chemistry. Herein we report a modified procedure for the synthesis of DA cyclobutanes that are activated by an alkoxy donor group and geminal diester withdrawing groups. Furthermore, the subsequent application of these cyclobutanes for the first time in imine dipolar cycloadditions to afford highly substituted piperidine and piperideine derivatives is also reported.

Scheme 2. Formal [4+2] cycloaddition of DA cyclobutanes and imines

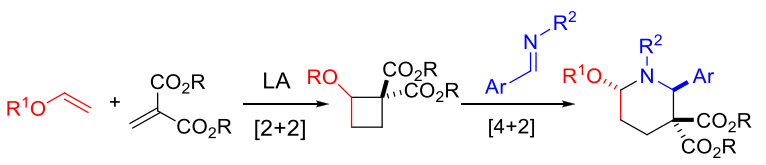

The 2-alkoxy-1,1-cyclobutane diesters are interesting latent 1,4-dipole equivalents that can be prepared from enol ethers and methylidene malonates. The preparation of this class of cyclobutanes was reported by Roberts in 1986 (Scheme 3), ${ }^{13}$ yet it was somewhat surprising that the use of these cyclobutanes in dipolar cycloadditions had not been realized prior to this work

Scheme 3. $\mathrm{ZnBr}_{2}$ mediated synthesis of DA cyclobutanes

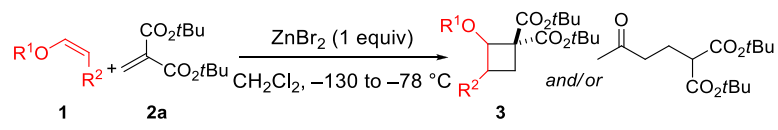

Duplication of the conditions reported by Roberts for the reaction of dihydropyran with di-tert-butyl methylidene malonate, in our hands, gave a poor yield (39\% Table 1, entry 1), and isolation of the cyclobutane was complicated by both considerable byproducts and the stoichiometric $\mathrm{ZnBr}_{2}$. More problematic, however, was our inability to extend this methodology to the more readily available and reactive diethyl methylidene malonate, and only trace amounts of the desired cyclobutane was observed along with a complex mixture of polymerization and ring opened byproducts (entry 2). A variety of other Lewis acids were then screened, and $\mathrm{Sc}(\mathrm{OTf})_{3}$ and $\mathrm{Yb}(\mathrm{OTf})_{3}$ quickly emerged as competent catalysts, with $\mathrm{Yb}(\mathrm{OTf})_{3}$ being the catalyst of choice due to slightly higher yields and lower catalyst cost (entries 5

(12) (a) Yu, M.; Pagenkopf, B. L. Org. Lett. 2003, 5, 5099-5101. (b) Morales, C. L.; Pagenkopf, B. L. Org. Lett. 2008, 10, 157-159. (c) Bajtos, B.; Pagenkopf, B. L. Org. Lett. 2009, 11, 2780-2783.

(13) (a) Baar, M. R.; Ballesteros, P.; Roberts, B.W. Tetrahedron Lett. 1986, 27, 2083-2086. (b) Mangelinckx, S.; Vermaut, B.; Roland, V.; De Kimpe, N. Synlett 2008, 17, 2697-2701. (c) Canales, E.; Corey, E. J. J. Am. Chem. Soc. 2007, 129, 12686-12687. 
and 6). The use of catalytic $\mathrm{Yb}(\mathrm{OTf})_{3}$ rather than stoichiometric $\mathrm{ZnBr}_{2}$ made the reactions operationally much simpler to perform (up to 12 gram scale), requiring only a simple filtration to provide the cyclobutane in high purity and yield.

Table 1. Optimizing cyclobutane formation

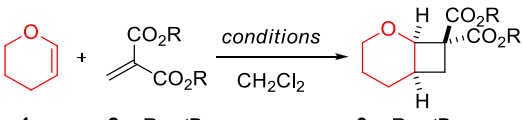

$$
\begin{aligned}
& \text { 1a } \quad \begin{array}{rlrl}
2 \mathrm{a}, \mathrm{R}=t \mathrm{Bu} & 3 \mathrm{a}, \mathrm{R}=t \mathrm{Bu} \\
\mathbf{2 b}, \mathrm{R}=\mathrm{Et} & 3 \mathrm{~b}, \mathrm{R}=\mathrm{Et}
\end{array}
\end{aligned}
$$

\begin{tabular}{ccccc}
\hline entry & $\mathrm{R}$ & catalyst & temperature & yield $(\%)^{\mathrm{a}}$ \\
\hline 1 & $t \mathrm{Bu}$ & 1 equiv $\mathrm{ZnBr}_{2}$ & $-130{ }^{\circ} \mathrm{C}$ to $-78{ }^{\circ} \mathrm{C}$ & $39^{\mathrm{b}}$ \\
2 & $\mathrm{Et}$ & 1 equiv $\mathrm{ZnBr}_{2}$ & $-130{ }^{\circ} \mathrm{C}$ to $-78{ }^{\circ} \mathrm{C}$ & $17^{\mathrm{b}}$ \\
3 & $\mathrm{Et}$ & 1 equiv $\mathrm{ZnCl}_{2}$ & $-130{ }^{\circ} \mathrm{C}$ to $-78{ }^{\circ} \mathrm{C}$ & $0^{\mathrm{c}}$ \\
4 & $\mathrm{Et}$ & 1 equiv $\mathrm{TMSOTf}$ & $-78{ }^{\circ} \mathrm{C}$ & $0^{\mathrm{c}}$ \\
5 & $\mathrm{Et}$ & 10 mol $\% \mathrm{Sc}(\mathrm{OTf})_{3}$ & $-78{ }^{\circ} \mathrm{C}$ & 78 \\
6 & $\mathrm{Et}$ & $10 \mathrm{~mol} \% \mathrm{Yb}(\mathrm{OTf})_{3}$ & $-78{ }^{\circ} \mathrm{C}$ & 84
\end{tabular}

${ }^{a}$ Isolated yield. ${ }^{b}$ Product contaminated by ring opened and polymeric substance. ${ }^{c}$ Polymeric substances observed.

Having identified $\mathrm{Yb}(\mathrm{OTf})_{3}$ as a superior catalyst for the synthesis of alkoxy substituted DA cyclobutanes, the feasibility of using it to catalyze the [4+2] cycloaddition of these cyclobutanes with imines was explored. ${ }^{14}$ To our delight, upon exposure of cyclobutane $\mathbf{3 b}$ and imine $\mathbf{4 a}$ (prepared in situ) to catalytic $\mathrm{Yb}(\mathrm{OTf})_{3}$ at $-50{ }^{\circ} \mathrm{C}$, the bicyclic piperidine $\mathbf{5 a}$ as a single diastereomer and piperideine 6a were observed (Scheme 4). On the other hand, reaction of imine $\mathbf{4 b}$ gave cycloadduct $\mathbf{5 b}$ as a $2: 1$ mixture of diastereomers as well as piperideine $\mathbf{6 b}$. The relative stereochemistry of trans-5b and cis-5b was assigned on the basis of NOE interactions, and ultimately confirmed by single-crystal X-ray analysis (Figure 1). In order to isolate only the piperideine product, the reaction was warmed to room temperature for an hour after consumption of the cyclobutane, to drive the product from the piperidine 5a to the piperideine $\mathbf{6 a}$.

Scheme 4. Formal [4+2] cycloaddition of alkoxy substituted DA cyclobutanes and imines

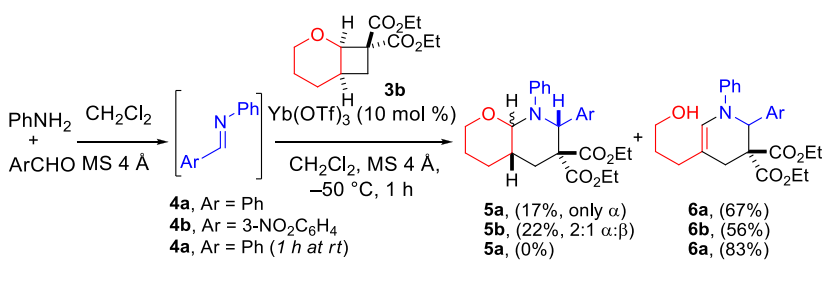

(14) (a) Marshman, R.W. Aldrichimica Acta 1995, 28, 77-84. (b) Shibasaki, M.; Matsunaga, S.; Kumagai, N. Acid Catalysis in Modern Organic Synthesis, Vol. 2 (Eds. H. Yamamoto, K. Ishihara), WILEYVCH, Weinheim, 2008, pp. 635-710.
Figure 1. Single crystal X-ray structures of trans-5b and cis-5b

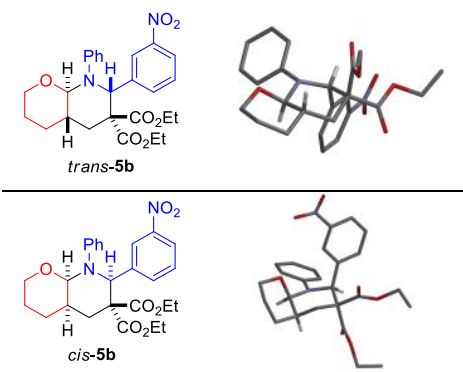

Having demonstrated that both the cyclobutane and piperideine syntheses were successful, the scope for both reactions was explored and the results are summarized in Table 2. In regard to the cyclobutane formation, the range of compatible methylidene malonates has been expanded beyond di-tert-butyl methylidine malonate to now encompass the more reactive diethyl- and dimethyl methylidine malonates. The range of enol ethers that participated in the cycloaddition was quite broad with cyclic, acyclic and higher-substitution patterns being tolerated (3b-g). Regarding the [4+2] reaction, electron deficient $(\mathbf{6 b}$ and $\mathbf{6 g})$ and electron rich $(\mathbf{6 c})$ aromatic $(\mathbf{6 a}$, 6e and $\mathbf{6 f}$ ) and hetereoaromatic (6d) imines participated. Unfortunately, the more reactive cyclobutanes $3 \mathbf{e}-\mathbf{g}$ gave complex mixtures when subjected to the same reaction conditions.

Scheme 5. $\mathrm{Yb}(\mathrm{OTf})_{3}$ catalyzed synthesis of DA cyclobutanes and piperideines

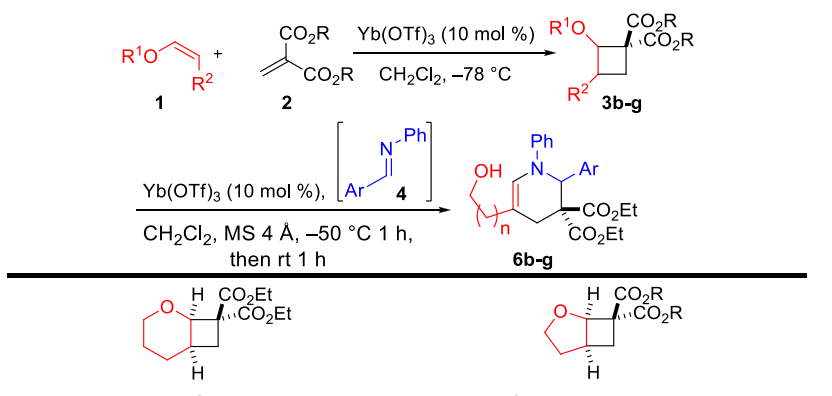

3b, $(84 \%)$

3c, $\mathrm{R}=\mathrm{Et}(93 \%)$

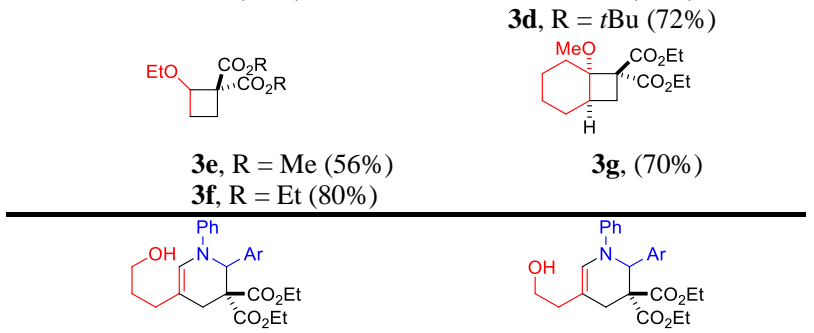

6b, $\left.\mathrm{Ar}=3-\mathrm{NO}_{2} \mathrm{C}_{6} \mathrm{H}_{4} 73 \%\right)$

6c, $\mathrm{Ar}=4-\mathrm{MeOC}_{6} \mathrm{H}_{4}(77 \%)$

6d, $\mathrm{Ar}=2$-thienyl $(42 \%)$

6f, $\mathrm{Ar}=\mathrm{Ph}(86 \%)$

6e, Ar = 2-naphthyl (84\%) 
Next, the ability of $\mathrm{Yb}(\mathrm{OTf})_{3}$ to catalyze the synthesis of cyclobutanes with carbon donating groups was explored (Scheme 6). The [2+2] reaction of methylidine malonates with $p$-vinyl anisole and anethole gave cyclobutanes $\mathbf{3 h}-\mathbf{3 k}$ as single diastereomers. Unfortunately, no reaction was observed with styrene and only polymerization products were observed. In contrast to the cyclobutanes activated by alkyl ethers, the cycloaddition of imines with cyclobutane $\mathbf{3 h}$ required higher temperatures and longer reaction times $\left(0{ }^{\circ} \mathrm{C}\right.$ for $10 \mathrm{~h}$ vs. $-50^{\circ} \mathrm{C}$ for $1 \mathrm{~h}$ ). Nonetheless, the cycloaddition provided pentasubstituted piperidines with electrondeficient or rich aromatic, cinnamyl, and heteroaromatic imines. All the cycloadducts $\mathbf{6 h}-\mathbf{m}$ were obtained in moderate to good yields and exclusively as the transdiastereomer. The cyclobutanes $\mathbf{3 i} \mathbf{-} \mathbf{3 k}$ failed to react productively with imines, and only decomposition was observed.

Scheme 6. Synthesis of cyclobutanes and pentasubstituted piperidines

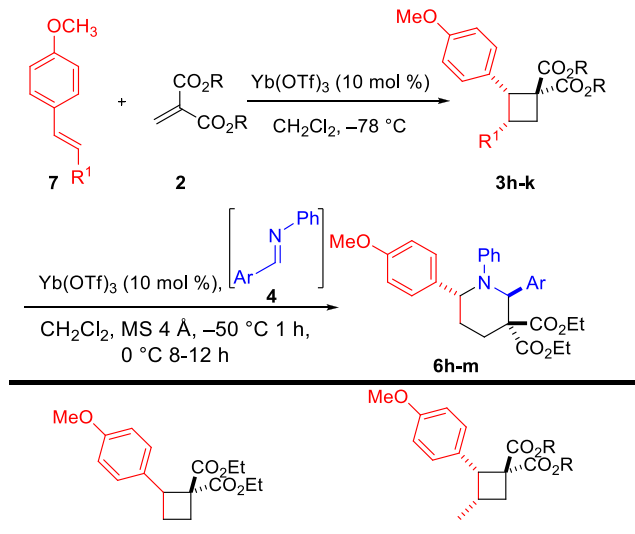

3h, $(81 \%)$

$3 \mathbf{i}, \mathrm{R}^{2}=\mathrm{Me}(51 \%)$

3j, $\mathrm{R}^{2}=\mathrm{Et}(71 \%)$

$3 \mathbf{k}, \mathrm{R}^{2}=t \mathrm{Bu}(59 \%)$

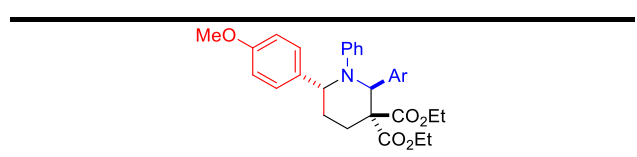

6h, $\mathrm{Ar}=\mathrm{Ph}(62 \%)$

6i, $\mathrm{Ar}=3-\mathrm{NO}_{2} \mathrm{C}_{6} \mathrm{H}_{4}(86 \%)$

6j, $\mathrm{Ar}=4-\mathrm{MeO} \mathrm{C}_{6} \mathrm{H}_{4}(73 \%)$

6k, Ar $=2$-thienyl $(59 \%)$

61, $\mathrm{Ar}=2$-naphthyl $(68 \%)$

6m, $\mathrm{Ar}=\mathrm{CHCPh}_{2}(61 \%)$ one-vessel three-step reaction sequence can be a practical option for large scale target-specific synthesis. ${ }^{15}$

Scheme 7. One pot, multi-step synthesis of piperideines

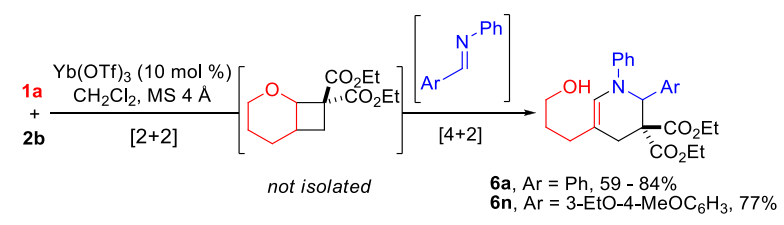

In summary, a new and reliable procedure for the preparation of alkoxy-substituted DA cyclobutanes has been developed, and these cyclobutanes have been shown for the first time to undergo dipolar cycloadditions. They undergo a smooth [4+2] cycloaddition with imines to afford highly substituted piperidines and piperideines. Additionally, a one pot procedure for cyclobutane synthesis and subsequent imine cycloaddition has been demonstrated. Efforts are currently underway to develop new cycloaddition reactions utilizing these cyclobutanes.

Acknowledgment. We thank the National Sciences and Engineering Research Council of Canada for financial assistance. We thank Prof. J. Peter Guthrie (UWO), Prof. Michael A. Kerr (UWO) and his group for helpful discussions. We thank Mr. Guerman Popov (UWO) and Ms. Jackie Price (UWO) for determination of the X-ray structures. We thank Mr. Andrew C. Stevens (UWO) for help with manuscript preparation. Mahmoud Moustafa thanks the Egyptian Academy of Scientific Research and Technology for financial support.

Supporting Information Available: General experimental procedures and characterization of all new compounds, and copies of NMR spectra. This material is available free of charge via the Internet at http://pubs.acs.org.
Finally, the possibility of carrying out the cyclobutane formation/imine cycloaddition reaction sequence in one reaction vessel was examined (Scheme 7). When a $\mathrm{CH}_{2} \mathrm{Cl}_{2}$ solution of imine was added to a concentrated solution of the in situ formed cyclobutane the cycloadduct was obtained in yields ranging from $(59-84 \%)$. While isolating the cyclobutane is advantageous for building chemical libraries, obviating cyclobutane isolation with a
(15) For a one-pot procedure, methylidene malonate should be freshly preapred. 